\title{
El aula como escenario de innovación docente 2.0
}

Alonso Pereira, José Ramón; Blanco Lorenzo, Enrique; Caridad Graña, Juan Antonio; Río Vázquez, Antonio S.

Grupo de Innovación Educativa en Historia de la Arquitectura, E. T. S. de Arquitectura

\section{RESUMEN}

Desde el año 2007 el Grupo de Investigación en Historia de la Arquitectura IALA de la Universidade da Coruña ha ido experimentando y desarrollando un conjunto de metodologías activas de innovación docente a través de la asignatura Introducción a la Arquitectura (Grado en Estudios de Arquitectura) sobre el estudio, análisis y comprensión del espacio arquitectónico empleando el aula como herramienta de aprendizaje. Frente a la distribución tradicional de un orador activo enfrentado a un alumno-receptor pasivo, la reconfiguración del aula en función del material de trabajo empleado en cada clase se han convertido en temas capitales. El alumno y sus recursos de aprendizaje son puestos en el centro de la atención pedagógica y del espacio arquitectónico considerando, al resto de los recursos de aprendizaje y al propio docente, como periféricos desde el punto de vista físico. En la experiencia llevada a cabo durante estos años en la Escuela Técnica Superior de Arquitectura de la Universidade da Coruña se le propone al alumnado la utilización del espacio del aula como espacio de su primera experiencia proyectual, que ha de reconfigurar progresivamente durante el curso, al tiempo que relaciona las ideas espaciales con los problemas funcionales y constructivos inherentes a la arquitectura.

PALABRAS CLAVE: Arquitectura, aprendizaje, aula, metodología, proyecto 


\section{CITA RECOMENDADA:}

Alonso Pereira, J. R. Blanco Lorenzo, E., Caridad Graña, J. A., Río Vázquez, A. S. (2018). El aula como escenario de innovación docente 2.0. En E. de la Torre Fernández (ed.) (2018). Contextos universitarios transformadores: retos e ideas innovadoras. II Xornadas de Innovación Docente. Cufie. Universidade da Coruña (pág. 261-270).

DOl capítulo: https://doi.org/10.17979/spudc.9788497496780.261

DOl libro: https://doi.org/10.17979/spudc. 9788497496780

\section{ABSTRACT}

Since 2007, the Research Group in History of Architecture IALA of the University of A Coruña has been experimenting and developing a set of active methodologies in teaching innovation through the subject Introduction to Architecture (Degree in Architecture Studies) on the study, analysis and understanding of the architectural space using the classroom as a learning tool. Confronted with the traditional distribution of an active speaker faced with a passive student-receiver, the reconfiguration of the classroom based on the work material used in each class have become major issues. The student and their learning resources are placed at the center of the pedagogical attention and the architectural space, considering the rest of the learning resources and the teacher himself, as peripherals from the physical point of view. In the experience carried out during these years in the Superior Technical School of Architecture of the University of A Coruña students are asked to use the classroom space as a space for their first project experience, which has to be reconfigured progressively during the course, to the time that relates spatial ideas to the functional and constructive problems inherent in architecture.

KEY WORDS: Architecture, learning, classroom, methodology, project 


\section{INTRODUCCIÓN}

Desde el año 2007 el Grupo de Investigación en Historia de la Arquitectura IALA, adscrito al Departamento de Proyectos Arquitectónicos, Urbanismo y Composición de la Universidade da Coruña ha ido experimentando y desarrollando un conjunto de metodologías activas de innovación docente a través de la asignatura Introducción a la Arquitectura, actualmente encuadrada en el primer cuatrimestre del Grado en Estudios de Arquitectura siendo la primera materia donde el alumno entra en contacto con el triple hecho reflexivo, proyectual y constructivo de la disciplina. Aunque la mayor parte de estas actividades se han centrado en la aplicación de las Tecnologías de la Información y la Comunicación en la docencia presencial y no presencial, generando un Entorno Virtual Docente (ENVIDO), articulado alrededor del blog de la asignatura (http://iala.udc.es/), también se han trabajado metodologías activas sobre el estudio, análisis y comprensión del espacio arquitectónico empleando el aula como herramienta de aprendizaje.

La preocupación por la docencia interactiva y la aplicación de las nuevas tecnologías a la docencia ha llevado al grupo IALA a la reflexión sobre el espacio del aula como espacio arquitectónico orientado a esta nueva docencia. La introducción del ordenador portátil, la tableta 0 el teléfono inteligente nos obliga a la reconsideración del aula en su concepción tradicional como espacio de aprendizaje. La distribución habitual de un orador activo enfrentado a un alumno-receptor pasivo está marcada por la obsolescencia del planteamiento y la ineficacia de sus resultados. En el nuevo modelo aplicado por IALA el profesor que actúa como guía debe tener la capacidad de orientar al alumno interactuando con los contenidos que, el propio alumno individualmente o como grupo busca, encuentra y propone. La capacidad de movimiento del profesor y el alumno en el aula, y la reconfiguración de ésta en función del material de trabajo propuesto y utilizado en cada clase se convierten en temas capitales. En el modelo aplicado el alumno y sus recursos de aprendizaje son puestos en el Centro de atención pedagógica y en el Centro del espacio arquitectónico considerando, al resto de los recursos de aprendizaje y al propio docente, como periféricos desde el punto de 
vista físico. En la experiencia llevada a cabo durante estos años en la Escuela Técnica Superior de Arquitectura se le propone, además al alumnado de modo específico, la utilización del espacio del aula como espacio de su primera experiencia arquitectónica, como lugar del proyecto, que ha de reconfigurar progresivamente a lo largo de la duración del curso hasta ajustarlo a las necesidades de aprendizaje de las que va tomando conciencia al tiempo que relaciona las ideas espaciales con los problemas funcionales y constructivos, algo que resulta de especial interés desde nuestra visión dual como profesores y arquitectos.

\section{DESCRIPCIÓN DE LA EXPERIENCIA}

La implantación del conocido como «Plan Bolonia» a través del Grado en Arquitectura, supuso la modificación sustancial de los modos de docencia y aprendizaje en las materias hasta ese momento impartidas. La puesta en marcha en la Escuela Técnica Superior de Arquitectura de la Universidad de A Coruña, de un nuevo plan de estudios adaptado al Espacio Europeo de Educación Superior en el año 2008, supuso una oportunidad para el desarrollo de nuevas estrategias para el aprendizaje y la docencia, pensando en las sesiones de docencia interactiva y en la existencia de un importante número de horas de trabajo no presencial del alumno fuera del aula.

\subsection{INTRODUCIÉNDONOS EN LA ARQUITECTURA DEL AULA}

En el curso inicial de la carrera, la asignatura de Introducción a la Arquitectura, como materia troncal, se propone comenzar la formación del futuro arquitecto atendiendo desde el inicio a un triple soporte esencial para la profesión: las componentes reflexiva, proyectiva y constructiva del hecho arquitectónico. La asignatura se plantea como objetivo despertar y/0 acrecentar el interés por la Arquitectura y por su razón ontológica, aproximándose a su definición desde la historia y la teoría y fomentando la capacidad analítica, el sentido crítico y el desarrollo lógico del alumno, trabajando, como territorio propio de la Arquitectura, desde la ciudad al diseño elemental. Se trata de aprender a ver, de aprender a pensar la Arquitectura. En 
este proceso se trabaja con arquitecturas paradigmáticas (aquellas que puede presentarse como los mejores ejemplos o modelos), emblemáticas (que sirven de referencia en un contexto determinado), pero también con arquitecturas inmediatas, que no tienen por qué ser relevantes en cuanto a su valor patrimonial pero constituyen un entorno óptimo de aprendizaje por su inmediatez y por ser experimentadas de modo directo por el usuario. En ese sentido, el aula es el mínimo funcional dónde el alumno desarrolla su formación, un auténtico «paisaje de aprendizaje» en palabras del arquitecto holandés Herman Hertzberger.

¿Qué herramientas debemos emplear para una adecuada docencia de la arquitectura? ¿Cuáles son los mecanismos adecuados para que un alumno de primer curso, sin apenas contacto con la disciplina, se vaya familiarizando con las herramientas de trabajo propias del arquitecto? En nuestra condición dual de profesores y arquitectos queremos formar a futuros profesionales desde el primer momento, que piensen en la arquitectura desde lo que tienen más próximo.

Tenemos muchas herramientas para lograr esas metas. Desde nosotros mismos hasta una herramienta que normalmente ignoramos: el aula. Podemos ver el aula como un hecho dado 0 plantearnos que el aula es un problema de proyecto. ¿Qué implica entender el aula como un auténtico escenario de aprendizaje susceptible de ser pensado y proyectado? No podemos obviar las palabras de Winston Churchill «We shape our buildings; thereafter they shape us».

El aula se convierte entonces en una útil herramienta para la docencia de la arquitectura, un entorno integrador orientado a la consecución de los objetivos previstos en la asignatura, un lugar de pensamiento, debate, análisis y proyecto.

\subsection{EL AULA COMO ESPACIO DE APRENDIZAJE (EXISTENZMINIMUM)}

Uno de los cambios más notables desde la implantación de la aplicación del llamado Plan Bolonia en la docencia universitaria fue la introducción de las nuevas tecnologías y los nuevos instrumentos de trabajo por parte de los miembros del Grupo de Innovación Educativa en Historia de la Arquitectura, en especial en la docencia interactiva, al tiempo que 
reflexionábamos como estos cambios deberían incidir en la reconsideración del aula como espacio arquitectónico para el aprendizaje.

La introducción del ordenador portátil, la tableta y/o el teléfono inteligente, como herramientas físicas para la docencia, el acceso a Internet y las posibilidades de uso de las redes sociales como ventanas de acceso al exterior, obligan a la reconsideración de la realidad física del aula como espacio arquitectónico especializado y proyectado para el aprendizaje (Fig. 1). Si el uso cambia es necesario el replanteamiento de la arquitectura que le da respuesta, en tanto que herramienta de innovación. El nuevo espacio arquitectónico para el aprendizaje superior continúa teniendo su célula básica, su existenzminimun, en el aula, pero esta tiene que ser redefinida en función de su nuevo uso.

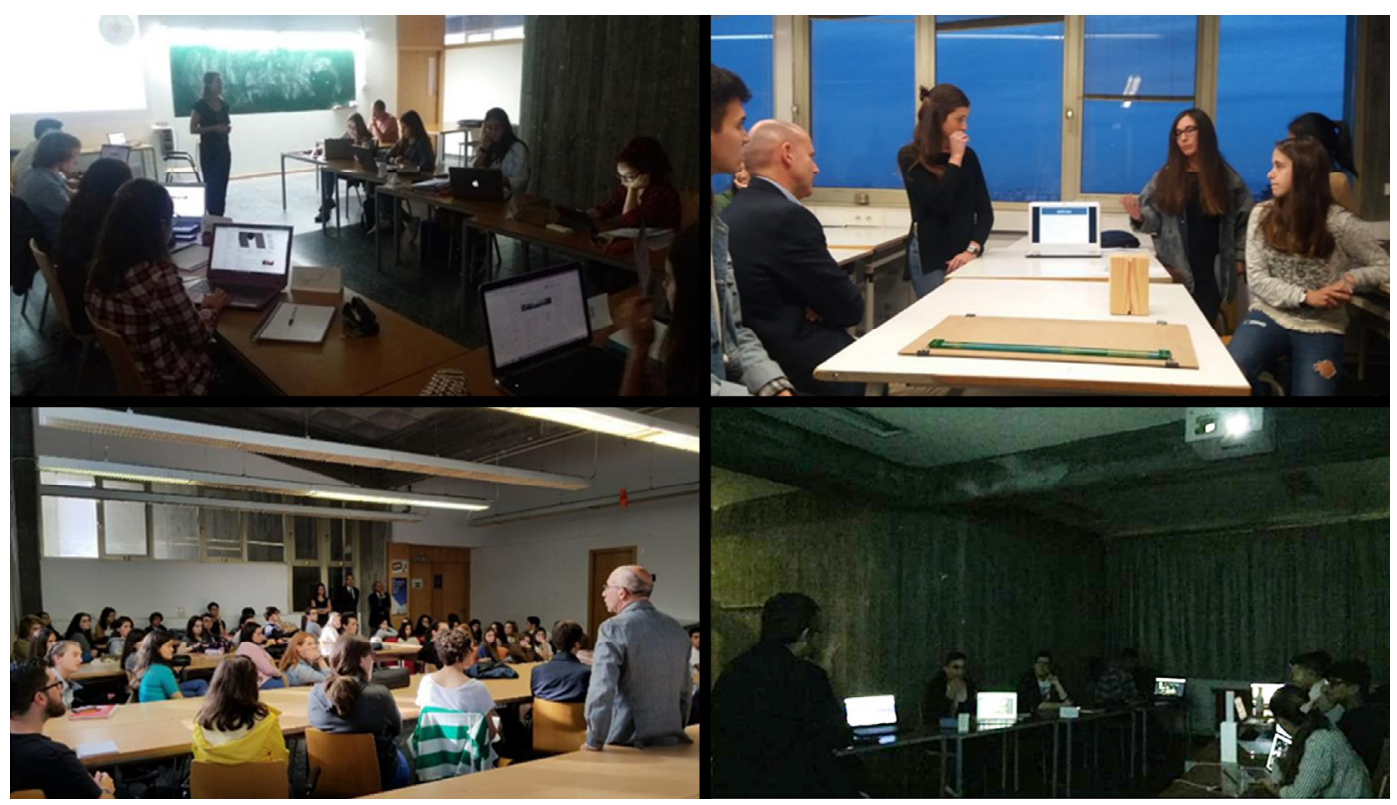

Fig. 1: Distintas posibilidades de uso del aula en la docencia de Introducción a la Arquitectura

A los instrumentos tradicionales de este espacio mínimo, pizarras, proyectores y mobiliario dispuesto en matriz orientada, pensados para la docencia expositiva tradicional, en la que un profesor-orador activo se enfrenta a un alumno-receptor pasivo, se opone un nuevo tipo de 
docencia interactiva que plantea diferentes modos de ocupación del espacio en función de los distintas clases de aprendizaje planteadas en relación con el objeto a conocer y del propio alumno como sujeto central de conocimiento. Trabajo individual, trabajo en equipo, aprendizaje por proyectos, aprendizaje emocional, aprendizaje a través de objetos 0 por simulación, constituyen técnicas pedagógicas que obligan a repensar el aula como espacio arquitectónico para convertirla en el principal instrumento innovador para el aprendizaje.

En este modelo contemporáneo el profesor, que actúa como guía debe tener la capacidad de orientar al alumno interactuando con los contenidos que el propio alumno individualmente 0 como grupo busca, encuentra, elabora y propone. El recorrido, el movimiento en el aula se convierte en elemento central de atención espacial, frente al valor de posición y la frontalidad tradicionales.

La capacidad de modificación espacial del aula, por parte de sus usuarios, en función de las necesidades y para adaptarse a las necesidades de percepción y movimiento del profesor y del alumno en el aula, se antojan centrales.

Para llevar adelante la experiencia se empleó, basada en la condición de arquitectos de los profesores de la asignatura, la metodología de trabajo del proyecto arquitectónico estructurada en los principios secuenciales e iterativos de análisis, ideación, composición, ejecución y uso. Los actores del trabajo fueron los propios alumnos, quienes a lo largo del cuatrimestre de duración de la asignatura, reconfiguraron el aula, moviendo el mobiliario en función de sus necesidades, elaborando planos y propuestas hasta alcanzar mejores resultados.

El profesor actúa como guía crítico sobre los resultados de su primer proyecto arquitectónico, introduciendo variables nuevas que obligan a reconsiderar la solución en un proceso de mejora constante.

Con esta experiencia no estamos trabajando con metodologías no planteadas con anterioridad, de hecho prácticas anteriores como la llevada a cabo en la escuela Bauhaus - centro paradigmático en la enseñanza de la arquitectura durante la primera mitad del siglo veinte- ya realizó trabajos de este tipo, utilizando el aula como espacio de la primera experiencia 
arquitectónica de los alumnos, como lugar del proyecto, analizando las posibilidades de reconfiguración, dibujando y planteando alternativas, entendiendo los problemas funcionales y constructivos que cada caso supone. Se trata de reutilizar actualizándolos de modo contemporáneo, recursos ya existentes.

\section{RESULTADOS}

La Escuela Técnica Superior de Arquitectura de A Coruña, creada en 1973, se sitúa en un edificio singular dentro de las arquitecturas del campus de la Zapateira, un proyecto de Juan Castañón Fariña y José María Laguna Martínez, que cuentan en la obra con la colaboración del arquitecto local Rodolfo Ucha Donate. Además de su estética que se puede encuadrar dentro del brutalismo internacional y su especial solución estructural, la Escuela destaca por nacer con un programa académico determinado que se refleja perfectamente en la organización espacial del edificio.

Con poco más de setenta estudiantes en sus comienzos, la Escuela fue creciendo año a año desbordando las más optimistas previsiones iniciales. Desde 1981 en que se graduó la primera promoción, han salido de ella más de un millar de profesionales, cuya presencia se evidencia hoy en Galicia. Durante estos años la Escuela se ha convertido en foco de las preocupaciones arquitectónicas de Galicia, generando una importante labor de reflexión y profundización sobre las raíces culturales del país, unida a una investigación continuada, plasmada en tesis, encuentros y congresos de gran resonancia a nivel internacional.

Durante su historia, la Escuela ha tenido 4 planes de estudio, prácticamente uno por década. Las transformaciones académicas han tenido como consecuencia cambios en la organización del edificio, desde aspectos tan elementales como el tamaño y capacidad de las aulas hasta la incorporación de las redes de información y comunicación que han ido surgiendo en los últimos años.

Los resultados que podemos observar en nuestra experiencia es que todos esos cambios nos han servido para entender la Escuela en general y el aula en particular como un proyecto vivo, 
en constante evolución. A nosotros, los profesores, nos ha ofrecido una materia prima útil para el aprendizaje. A los alumnos les ha permitido un lugar de experimentación, donde además pueden observar la realidad histórica construida, con las correspondientes permanencias y cambios que se han producido.

Temas tan habituales en la actualidad como haber pasado de una clase totalmente focalizada hacia una pantalla donde se proyectaban diapositivas, a un ambiente de multipantallas, donde el alumno puede ajustar su modo de visualización; las posibilidades de organización que ofrece el mobiliario, ya sea fijo o móvil o nuestra manera de ubicarnos dentro del espacio, son aspectos inherentes al proyecto de arquitectura. Ignorarlos supone dejar de lado una oportunidad magnífica para introducirse en la arquitectura y en su razón de ser.

\section{CONCLUSIONES}

La utilización del aula como espacio de aprendizaje dentro de la docencia de Introducción a la Arquitectura supone a la vez una fortaleza y una oportunidad para la consecución de los objetivos de motivar el interés del alumno y transmitir los conocimientos previsto en el proceso de Bolonia. Para lograrlo se ha planteado que espacios y metodologías de aprendizaje vayan de la mano. Como reflexión final nos gustaría transmitir nuestro interés por continuar desarrollando estas experiencias de un modo transmisible, para que se pudieran abrir a nuevos territorios y usuarios, pensando en la mejora e innovación permanente, podría ser de gran interés el intercambio de conocimiento con aquellas experiencias internacionales homologables identificadas, con el objetivo de generar valor añadido y feedback.

\section{REFERENCIAS}

- Norberg-Schulz, Christian (1990). Louis I. Kahn, idea e imagen. Madrid: Xarait

- Aicher, Otl (1994). El mundo como proyecto. Barcelona: Gustavo Gili, SL

- VVAA (1998). Louis I. Kahn. Conversations with students. New York: Rice University School of Architecture / Princenton Architecture Press. 
- Castells, Manuel; Borja, Jordi (2004). Local y global. La gestión de las ciudades en la era de la información. Madrid: Taurus

- Hertzberger, Herman (2005). Lessons for Students in Architecture. Rotterdam: 010 Publishers.

- Hertzberger, Herman (2008). Space and Learning. Rotterdam: 010 Publishers. 